\title{
Mensurando a qualidade da democracia na VenezuelaI
}

\author{
Rafael Mucinhato*
}

Resumo: Por meio da aplicação do modelo de qualidade da democracia elaborado pelos autores Larry Diamond e Leonardo Morlino, analisaremos as diferentes dimensões do modelo de democracia implantado na Venezuela desde a chegada de Hugo Chávez ao poder. Argumentamos que o modelo implantando na Venezuela não pode ser considerado como inexoravelmente rumando a um autoritarismo, mas sim um modelo que opta por enfatizar dimensões as quais outros governos não tomam como prioritárias para uma democracia substantiva.

Palavras-chave: Venezuela, qualidade, democracia, Hugo Chávez.

\section{Introdução}

O processo político pelo qual a Venezuela passa é um dos mais peculiares da história política latino-americana. Nesse país, sempre colocado como exemplo de democracia no continente (REY, 1980; O’DonNELl, 1998; VILLA, 2005), os partidos Ação Democrática (AD) e Comitê de Organização Política Eleitoral Independente (COPEI) por décadas se alternavam no poder. Porém, décadas de uma democracia que apresentava a maior renda per capita da América Latina e era um modelo de democracia para os observadores internacionais, com suas eleições regulares, instituições estáveis, direitos civis respeitados e seus partidos com sólidas bases sociais (NETO, 2003), não foram capazes de acabar com problemas como a desigualdade social, a má distribuição de renda e o desemprego - que foi de 15,4\% em 1993 (MARINGONI, 2004). Ao cabo, no final da década de 1980, esse sistema político ruiu em meio a inúmeros escândalos de corrupção, impulsionado por uma revolta popular de grandes proporções (o El Caracazo, de 29 de fevereiro de 1989) que levou posteriormente ao processo de impeachment do presidente social-democrata Carlos Andrés Pérez, em 1993.

Nas eleições presidenciais de 1998, o cenário político apontava uma nova figura política que já vinha em ascensão: Hugo Rafael Chávez Frías. Chávez acabou

\footnotetext{
I Agradeço as observações feitas pelo prof. Rogério Arantes, quando da realização da disciplina Política Comparada, da qual resultou este trabalho. Agradeço a Fabrício Vasselai pelas críticas apontadas e pela revisão final do texto. Agradeço também às críticas feitas pelos pareceristas da Primeiros Estudos a uma versão anterior deste texto. Incorporadas na medida do possível, elas amenizaram suas deficiências.

${ }^{*}$ Graduando em Ciências Sociais - USP.
} 
por ser eleito com um projeto político que alterou profundamente a orientação política do governo rumo ao chamado "Socialismo do Século XXI", representando um "divisor de águas" na política venezuelana (VILLA, 2005) e iniciando a chamada "V República". Em sua campanha, o então candidato apresentara um projeto político baseado na democracia participativa e na ideia de um povo culturalmente inspirado por uma vocação pan-americana universalista (o ideário de integração latinoamericana de Simon Bolívar).

Assim, baseado no crescente descontentamento popular com o desempenho de um modelo de democracia em que a participação popular era baixa nos rumos das políticas públicas, a candidatura de Chávez cresce pela sua proposta de que a democracia deveria ter novas prioridades. Considerando que a concepção de democracia de um determinado país é baseada em escolhas políticas, o modelo que era adotado até então não mais correspondia aos anseios populares de maior participação e igualdade? Nesse sentido, o modelo pelo qual o país optara no "Pacto de Punto Fijo"1 teria se esgotado? Sendo assim, o governo Chávez acaba tomando como prioridade certas dimensões da democracia em possível detrimento de outras? Quais seriam essas dimensões? Há trade-offs entre elas?

A chamada Revolução Bolivariana sofre constantes críticas, por parte de acadêmicos e governantes, quanto ao seu "modelo democrático". Análises recentes indicam que a Venezuela caminha inexoravelmente para um governo autoritário, com base numa visão um tanto determinista e, como será mostrado ao longo do texto, possivelmente baseada em um juízo de valor. Tal fato se observa no editorial de 21 de agosto de 1999 no jornal The New York Times, que acusa o presidente venezuelano de demonstrar "escasso respeito pelos mecanismos democráticos, e os venezuelanos deveriam estar preocupados com os métodos que utiliza para concentrar poderes em suas mãos". Assim como na entrevista do cientista político Guillermo O'Donnell, concedida ao jornal $O$ Estado de São Paulo em 17 de maio de

\footnotetext{
1 Pacto realizado entre os dois grandes partidos, o AD e o COPEI, que estabelecia os termos para a democracia, incluindo alguns elementos substantivos, como do campo econômico, assim como elementos procedimentais , de respeitar os resultados das eleições e consultar os lideres do partido de oposição (VILLA, 2005).
} 
2009, na qual o entrevistado disse: “Caminho para o autoritarismo? 'Com Chávez, certamente"'"2.

Para analisar o governo venezuelano e seu sistema político, utilizarei o modelo de Qualidade da Democracia elaborado na obra "Assessing the quality of democracy", editada por Larry Diamond e Leonardo Morlino. Tentarei argumentar que o governo venezuelano seria sim democrático, demonstrando quais foram as dimensões do modelo as quais o governo toma como prioridade, os trade-offs existentes entre as dimensões e exemplificando-as com algumas políticas públicas implantadas pelo governo.

Deve-se, antes de mais nada, apontar uma definição de democracia que norteie a discussão que será aqui colocada. Para além de uma visão "minimalista" de democracia, definida pelo próprio Morlino (2008a) como um regime que garanta o sufrágio universal, as eleições competitivas, livres e frequentes, a existência de mais de um partido político e mais de uma fonte de informação; considero esse conceito para além disso. Inclui-se nessa definição, além de instituições de representação dos cidadãos no sistema político, como os partidos e o parlamento (condições necessárias, mas não suficientes), a garantia de que essas instituições assegurem a distribuição do poder de tomar decisões que afetam a coletividade e assegurem também a participação dos cidadãos na avaliação e no julgamento que fundamenta o processo de tomada dessas decisões (MoISÉs; CARNEIRo, 2008). Para além disso, enfatizo a dimensão "igualdade" (política e também socioeconômica) do modelo analítico utilizado, muitas vezes relegado em detrimento da ideia de liberdade, apesar da "igualdade" ser, também, fundamental para uma democracia substantiva.

\section{0 modelo de qualidade democrática}

Segundo Diamond e Morlino (2005), um regime democrático de qualidade implicaria a satisfação das expectativas dos cidadãos no que concerne a governança (qualidade nos resultados). Um regime que permita aos cidadãos, às associações

\footnotetext{
2 A íntegra da entrevista encontra-se disponível no sítio da Faculdade Latino-Americana de Ciências Sociais no Brasil (FLACSO), <http://flacso.org.br>, e no próprio sítio do jornal, <www.estadao.com.br $>$.
} 
e às comunidades desfrutarem de extensa liberdade e igualdade política (qualidade de conteúdo); que proporcione um contexto em que todos os cidadãos possam julgar as ações do Estado mediante eleições e em que também haja controle recíproco entre as instituições e os funcionários públicos (qualidade no processo).

Assim, os autores definem as oito dimensões nas quais a democracia varia em qualidade: primado da lei, participação, competição, accountability vertical e horizontal $^{3}$, respeito pelas liberdades civis/políticas, implementação progressiva de igualdade política e, por último, responsividade 4 . As cinco primeiras concernem a dimensões procedimentais, a sexta e a sétima são dimensões substantivas e a última faz uma articulação entre procedimento e substância ao mensurar o quanto as políticas públicas correspondem às demandas civis. Os autores também argumentam que há uma articulação entre essas dimensões, seja pela dependência recíproca, ou pelos trade-offs de uma para com a outra.

Nesse sentido, serão exploradas cada uma das dimensões pelos dados socioeconômicos e/ou observações empíricas, buscando explicitar as articulações que elas apresentam entre si.

\section{0 primado da lei}

Para que o primado da lei (the rule of law) seja democrático, segundo O`Donnell (2005) - autor do capítulo acerca desse tema na obra de Diamond e Morlino -, o sistema legal deve defender os direitos políticos, civis e os procedimentos democráticos, deve também reafirmar a autoridade de accountability horizontal de outras agências e órgãos, e a lei deve ser igualmente reforçada e disseminada sobre todos. Na falta desses fatores, a participação política de setores menos privilegiados e marginalizados pela sociedade será prejudicada e, assim, a partici-

\footnotetext{
${ }^{3}$ A noção de accountability não possui uma tradução literal para o português. Ela vai além do conceito de responsabilidade, traz também a noção de dever, de obrigação de resposta. A accountability supõe a obrigação de governos e líderes eleitos de responder por suas decisões políticas aos cidadãos diretamente e por meio de poderes e órgãos constitucionais específicos. Enquanto o direito de voto garante a accountability vertical, por meio da qual os eleitores premiam ou punem o desempenho dos governantes, a accountability horizontal ou interinstitucional depende da existência de instituições e atores com expertise e poder específico para fiscalizar, controlar e corrigir ações ilícitas de atores públicos e governantes (MoISÉs, 2011).

${ }^{4}$ Responsividade democrática é o que ocorre quando o processo democrático induz o governo a formar e implementar políticas que os cidadãos querem. Quando o processo induz tais políticas consistentemente, consideramos a democracia com alta qualidade (POWELL JR., 2005).
} 
pação individual estará prejudicada em favor daqueles que têm maior disponibilidade de recursos e informação, podendo levar ao abuso de poder. Assim, a educação - cujo desempenho avançou substancialmente no governo Chávez, como será mostrado em outra dimensão - mostra-se como capital para que a população tenha uma capacidade cognitiva perante as leis e os processos de tomada de decisão, fator importante para que também haja igualdade.

Como compromisso de campanha, Chávez propusera a convocação de uma Assembleia Constituinte para "refundar a República". A proposta foi aprovada, sendo a nova Constituição Bolivariana da Venezuela referendada pelo voto em 15 de dezembro de 1999, fazendo com que, no discurso do governo, o respeito aos princípios constitucionais se tornasse pedra angular do governo de Chávez. Setores da população que participaram intensamente dos debates que deram origem a nova constituição se sentiram protagonistas do projeto (MARINGONI, 2004) e defenderam-na até fisicamente, quando da tentativa de golpe contra o governo Chávez em 2002, amparando-se em artigo da Constituição:

Art. 333 - Esta Constituição não perderá sua vigência se deixar de se observar por ato de força ou porque foi derrubada por qualquer outro meio distinto aos previstos nela. Em tal eventualidade, todo cidadão ou cidadã, investido ou não de autoridade, terá o dever de colaborar com o restabelecimento de sua efetiva vigência. (Constitución de La República Bolivariana de Venezuela, 1999) 5

Uma importante medida implementada pelo governo para que seja garantido o primado da lei foram os chamados "Círculos Bolivarianos". Eles estimulam a participação cívica da população para que se formem grupos de discussão, variando de 7 a 11 pessoas, onde são debatidos os problemas da região e a própria Constituição, a fim de que conheçam seus próprios direitos e deveres. Tal medida foi amplamente aceita pelos setores menos privilegiados da população, com especial destaque para a população dos chamados barrios (favelas) de Caracas. Assim, para Diamond e Morlino (2005), a Constituição deve ser suprema e disseminada, cabendo aos tribunais defendê-la - no caso da Venezuela, tal defesa estende-se à população como um todo.

\footnotetext{
5 Tradução do autor, assim como das próximas citações retiradas da mesma fonte.
} 
Outro exemplo da busca pelo cumprimento da lei será mostrado na dimensão "liberdade" do modelo, quando da não-renovação do direito de transmissão da rede televisiva RCTV.

\section{Participação}

Participação também é fator importante para uma democracia de qualidade. Segundo os autores do modelo, ela não deve se restringir somente ao momento do voto, mas também no que concerne ao rumo dos partidos políticos e das políticas públicas, às organizações da sociedade civil e na comunicação com aqueles que detêm cargos públicos. Para tal, seria fundamental o surgimento de uma cultura política, cívica, que valorize a participação e a igualdade de importância de todos os cidadãos.

A Constituição referendada em dezembro de 1999, segundo a cientista política venezuelana Margarita López-Maya, aprofunda a democracia política por meio da incorporação de diversos mecanismos de participação direta (MARINGONI, 2004). Os Poderes Públicos elevam-se para cinco, incluindo agora os poderes Cidadão e Eleitoral, e é introduzido um inovador mecanismo de soberania popular e de contestação pública, expresso no artigo 72 da Carta:

Todos os cargos e magistraturas de eleição popular são revogáveis. Transcorrida a metade do período para o qual foi eleito o funcionário ou funcionária, um número não menor que $20 \%$ dos eleitores e eleitoras inscritos [...] poderá solicitar a convocação de um referendo para revogar seu mandato.

A nova Constituição bolivariana contempla quatro diferentes tipos de referendo: o consultivo, sobre grandes projetos nacionais; o revogatório; o aprobatório, para aprovar projetos; e o anulatório, para abolir leis. Nesse sentido, para operacionalizar e mensurar o conceito de participação, pode-se fazer uso dos índices de participação eleitoral nos referendos dos últimos 10 anos de governo, mesmo com a ressalva feita anteriormente. Segundo Lijphart (2003), a participação eleitoral é um excelente indicador da qualidade democrática, principalmente em países onde o voto não é obrigatório, caso da Venezuela, por dois motivos. Primeiro, mostra o grau de interesse dos cidadãos em serem representados. Segundo, a partici- 
pação é fortemente relacionada ao status socioeconômico e pode, dessa forma, servir também como indicador indireto da igualdade política: alto índice de comparecimento significa participação mais igualitária e, assim, maior igualdade política. Baixo comparecimento quer dizer participação desigual e, por isso, maior desigualdade política. Isso, mais uma vez, comprova a inter-relação existente entre as dimensões do modelo teórico aqui apresentado. Abaixo, o índice de comparecimento nos referendos aplicados de 1999 a 2009 no governo Chávez.

Tabela I - Referendos realizados na Venezuela de 1999 a 2010

\begin{tabular}{llc}
\hline Data & Descrição do referendo & $\begin{array}{c}\text { Índice de compa- } \\
\text { recimento }\end{array}$ \\
\hline Dez/1999 & Aprovação da nova Constituição & $44,4 \%$ \\
\hline Jul/2000 & Legitimação do cargo de presidente & $56 \%$ \\
\hline Ago/2004 & Referendo pela revogação do mandato presidencial & $70 \%$ \\
\hline Out/2007 & Referendo pela Reforma Constitucional & $55,1 \%$ \\
\hline Fev/2009 & Possibilidade de uma nova candidatura presidencial & $70 \%$ \\
\hline Fonte: CNE, Consejo Nacional Electoral, órgão vinculado ao Poder Electoral &
\end{tabular}

Há outras evidências que comprovam a hipótese de que a participação popular seria uma das prioridades do novo governo, como a multiplicação das novas organizações populares que influenciam nas políticas públicas (como os Círculos Bolivarianos e os Comitês de Terras urbanas), mas a sua análise excede os limites deste artigo. Assim, a realização de cinco referendos com altos índices de comparecimento em um prazo de dez anos, para além das oito eleições realizadas no mesmo período, evidencia a ênfase dada na dimensão "participação" pelo governo.

\section{Liberdade}

A liberdade é a esfera mais controversa na democracia venezuelana. Ela consistiria de três tipos de direitos: quanto às liberdades civis (segurança, privaci-

${ }^{6}$ Consejo Nacional Electoral, <www.cne.gob.ve> . Acesso em jul. 2010. 
dade, liberdade de expressão, de religião, de pensamento), políticas (de votar e ser votado, de se organizar politicamente de maneira livre, fazer campanha) e sociais (saúde, educação, aposentadoria). Uma condição assegurada de liberdade também requer condições institucionais de justiça e de accountability vertical, com respeito à participação e à competição, assim como um Poder Judiciário constituinte.

Como exemplo para operacionalizar o conceito de liberdade e tratar seus trade-offs com outras dimensões, cabe uma análise da polêmica acerca da não renovação da concessão de transmissão da Rádio Caracas Televisión, a RCTV, anunciada em 28 de dezembro de 2006 e cumprida em 27 de maio de 2007. 0 fato foi utilizado por opositores do governo venezuelano e por outros países para alertar o mundo sobre o rumo autoritarista do governo Chávez, alegando violações ao direito de liberdade de expressão. Em contrapartida, o governo alegava estar assegurando o cumprimento da lei, amparando-se na Constituição.

O conceito de concessão é definido no Dicionário Aurélio da Língua Portuguesa como o "privilégio concedido pelo Estado a uma empresa ou indivíduo para que explore um serviço de utilidade pública ou recursos naturais por um determinado período de tempo". Assim, a não renovação, nos argumentos do governo, teria a finalidade de ampliar o domínio público dos meios de comunicação, um processo de democratização e desconcentração, amparando-se na aplicação dos artigos 108 e 113 da Constituição:

Art. 108 - Os meios de comunicação social, públicos e privados, devem contribuir para a formação cidadã. 0 Estado garantirá serviços públicos [...] com o fim de permitir o acesso universal à informação.

Art. 113 - Não se permitirão monopólios. Declaram-se contrários aos princípios fundamentais desta Constituição qualquer ato, atividade, conduta ou acordo dos ou das particulares que tenham por objetivo o estabelecimento de um monopólio [...].

No ano de 2006, segundo dados do governo, a concentração dos meios de comunicação televisivos encontrava-se da seguinte maneira:

\section{TV VHF - 78\% setor privado; $22 \%$ setor público TV UHF - $82 \%$ setor privado; $18 \%$ setor público Fonte: Livro Branco sobre a RCTV (2007)7.}

\footnotetext{
7 Dossiê elaborado pelo Ministério do Poder Popular para a Comunicação e Informação (MPPCI), que contou com a colaboração da Comissão Nacional de Telecomunicações (CoNATEL), órgão regulador do setor responsá-
} 
Quando da divulgação da não renovação, a oposição venezuelana, governos de outros países, como o britânico e o estadunidense, e a mídia privada uniram-se em uma campanha em defesa da RCTV, alegando que a não renovação de sua concessão, que já durava 53 anos, violava o direito democrático da liberdade de expressão - o que de fato o fazia. Assim, enquanto setores governistas qualificavam a oposição como antidemocrática, a oposição por sua vez dizia o mesmo do governo.

A decisão de não renovação explicitaria, assim, a hipótese de que a democracia venezuelana prioriza a participação e a igualdade, sendo a nacionalização de uma emissora televisiva uma forma de expressar esse processo. 0 sinal que era utilizado pela RCTV passou a um canal de domínio público, a TVes, evidenciando uma supressão de liberdades básicas, no caso, a de contestação, em prol da igualdade e da participação. Digo isso, pois a RCTV claramente se posicionava contra o governo Chávez, tendo recebido inúmeros processos ao longo dos anos pela divulgação de conteúdos que fizessem "apologia ao delito, incitação a rebelião e a subversão da ordem pública".

\section{Competição}

No que concerne à competição, os autores afirmam que, para que um sistema democrático seja considerado competitivo, deve haver eleições regulares e livres, com competições eleitorais justas entre diferentes partidos políticos. Porém, as democracias podem variar no grau de competitividade em razão de fatores como: o financiamento dos partidos políticos, o acesso de novas forças políticas à arena eleitoral, o sistema eleitoral, uma comissão eleitoral independente e a igualdade de acesso à mídia. Uma condição primordial para a competição seria o sistema legal, e, nesse quesito, encontramos na carta venezuelana os artigos 52, 53 e 67, que garantem o direito de associação (pública ou privadamente) com fins lícitos e para fins políticos. Ademais temos o artigo 68, que garante o direito de livre manifestação, desde que pacificamente ${ }^{8}$. 0 cumprimento desses princípios e o respeito

vel pela outorga ou renovação (por tempo limitado) da condição de concessionário a uma pessoa física ou jurídica.

${ }^{8}$ Art. 52 - Toda pessoa tem o direito de associar-se com fins lícitos [...] 0 Estado está obrigado a facilitar o exercício desse direito. 
a eles podem ser verificados pela livre organização de partidos opositores ao governo e pelas suas frequentes manifestações organizadas na capital Caracas.

Quanto à regularidade das eleições na Venezuela, abaixo apresento os oito últimos pleitos que colocaram em disputa os mais diversos cargos públicos.

Tabela II - Eleições realizadas na Venezuela de 2000 a 2010

\begin{tabular}{ll}
\hline Data & Descrição da eleição \\
\hline 30/jul/2000 & $\begin{array}{l}\text { Eleições gerais. Foram eleitos representantes para os cargos de presidente da Repú- } \\
\text { blica, deputados para a Assembléia Nacional, para os Conselhos Legislativos Estadu- } \\
\text { ais, para o Parlamento Latino-Americano e para o Parlamento Andino, assim como } \\
\text { para alguns cargos de prefeito }\end{array}$ \\
\hline 3/dez/2000 & Eleições para as Câmaras Municipais \\
\hline 31/out/2004 & $\begin{array}{l}\text { Eleições para o cargo de governador, deputados dos Conselhos Legislativos Estadu- } \\
\text { ais e vereadores }\end{array}$ \\
\hline 7/ago/2005 & $\begin{array}{l}\text { Eleições municipais } \\
\text { Eleições gerais para a Assembléia Nacional, 12 deputados para o Parlamento Latino- } \\
\text { Americano e 5 para o Parlamento Andino }\end{array}$ \\
\hline 3/dez/2006 & Eleições para presidente e para alguns cargos de prefeito \\
\hline 23/nov/2008 & $\begin{array}{l}\text { Eleições para governador, deputados dos conselhos estaduais, e para alguns cargos } \\
\text { de prefeito e conselheiros distritais }\end{array}$ \\
\hline Fonte: CNE & $\begin{array}{l}\text { Eleições gerais para a Assembleia Nacional assim como para 12 cargos de deputados } \\
\text { do Parlamento Latino-Americano }\end{array}$ \\
\hline
\end{tabular}

Ao total, contando com os referendos realizados, até a data de conclusão deste artigo, os venezuelanos do distrito federal de Caracas já foram às urnas 13 vezes desde a primeira eleição de Chávez, em 1998, mostrando que o sistema político venezuelano realiza eleições regulares.

Quanto à existência de partidos políticos, 31 partidos apresentaram-se ao pleito de 2005 para o cargo de deputado da Assembleia Nacional, enquanto que

Art. 53 - Toda pessoa tem o direito de reunir-se, pública ou provadamente, sem permissão prévia, com fins lícitos e sem armas. As reuniões em locais públicos reger-se-ão pela lei.

Art. 67 - Todos os cidadãos ou cidadãs têm o direito de associar-se com fins políticos, mediante métodos democráticos de organização, funcionamento e direção [...] e a concorrer aos processos eleitorais [...].

Art. 68 - Os cidadãos e cidadãs têm o direito de se manifestar, pacificamente e sem armas, sem outros requisitos que os que estabeleçam a lei (Constitución de La República Bolivariana de Venezuela, 1999; tradução do autor).

${ }^{9}$ Consejo Nacional Electoral. Acesso em abr. 2010. 
quatro partidos anunciaram boicote ao pleito (de acordo com o Consejo Nacional Electoral). Os oposicionistas propuseram um boicote à eleição, alegando que o governo controla o Conselho Nacional Eleitoral e que as máquinas de votação eletrônica "não são confiáveis". Em um relatório elaborado por José Silva Peneda, deputado do Parlamento Europeu, chefe de uma delegação da União Europeia para acompanhar essas mesmas eleições, deixou-se registrado que "os meios postos à disposição das forças do governo e da oposição eram muito desproporcionados a favor do governo e que a presença constante do presidente da República em programas de televisão (fato a ser analisado adiante) não contribuía em nada para a atenuação da tensão social".

Para além disso, vale ressaltar que o quadro partidário venezuelano passou por uma importante mudança no final de 2008, quando da criação do Partido Socialista Unido da Venezuela, o PSUV, que se tornou o maior partido do país em número de filiados e de cadeiras na Assembleia Nacional, com 139 das 167 cadeiras. A criação do partido modificou o equilíbrio de forças existente entre os partidos e deu mais força ao governo. Tal fato, além das constantes aparições do presidente, que também é o presidente do PSUV, coloca em discussão se o quadro partidário venezuelano ainda se apresenta como competitivo. Não cabe analisar essas deficiências no equilíbrio de forças neste artigo, dado o fato que quando da finalização deste artigo (setembro de 2010), apenas um pleito havia sido realizado com essa nova correlação de forças e o resultado completo ainda não havia sido divulgado.

Quanto a contar com um poder eleitoral que garanta a competitividade, a Constituição Venezuelana apresenta como peculiaridade o Poder Eleitoral, de natureza nacional e autônoma e tendo como órgão diretor o Conselho Nacional Eleitoral, além de organismos subordinados. Tal instituição surge a partir da visão do governo de que haveria uma falta de credibilidade dos processos eleitorais no país. Nesse sentido, a instituição alega ser "autônoma, despartidarizada e transparente". A composição do Conselho Nacional Eleitoral comprova em partes a proposta: “0 Conselho Nacional Eleitoral está integrado por cinco pessoas não vinculadas a organizações políticas: três deles postulados pela sociedade civil, um pelas faculdades de Ciências Políticas e Jurídicas das Universidades Nacionais e um pelo Poder Cidadão". Cabe aqui uma ressalva: apesar de o órgão garantir a realização de elei- 
ções frequentes, a não filiação partidária daqueles que compõem o Conselho não necessariamente pressupõe a sua despartidarização, haja visto que um cidadão pode ter grande simpatia pela "Revolução Bolivariana" e não necessariamente ser filiado ao PSUV.

Quanto à legislação eleitoral, a Venezuela apresenta a "Lei Orgânica do Poder Eleitoral", que tem como princípio fundamental seu artigo segundo:

\begin{abstract}
O Poder Eleitoral, como entidade que garante a fonte criadora dos poderes públicos mediante o sufrágio, fundamenta seus atos na preservação da vontade do povo, expressa através do voto no exercício de sua soberania.
\end{abstract}

Fonte: "Ley orgânica del Poder Electoral" (2002).

Assim, apesar das instituições criadas pela nova Constituição e da realização de eleições regulares, a existência de um partido do governo tão grande faz com que o grau de competição do modelo de democracia venezuelano seja afetado.

\title{
Accountability vertical
}

Accountability vertical seria a obrigação, por parte dos líderes políticos eleitos, de informar e de justificar aos cidadãos sobre suas ações políticas, e, por parte dos cidadãos, de julgar as ações destes primeiros, punindo-os ou recompensandoos, principalmente por meio do voto. Genericamente falando, seria uma espécie de "monitoramento político" e "prestação de contas".

A primeira forma de accountability vertical, o papel de informação, na sociedade venezuelana é principalmente cumprido pelas TVs estatais, como a Venezuela Televisión (VTV) e o Canal 8, e pelo programa dominical do governo, o "Aló Presidente" (analisado adiante).

A forma eleitoral de accountability vertical depende da realização de eleições regulares, fator que também se reflete na avaliação da competitividade de um governo. Como visto no item anterior, as eleições na sociedade venezuelana são um acontecimento frequente, por meio das quais os cidadãos podem punir ou recompensar os políticos que já exerceram um mandato. Cabe aqui mais uma vez a ressalva quanto ao grau de competitividade dos partidos da sociedade venezuelana, no desigual grau de acesso de todas as forças políticas aos meios de comunica- 
ção após a reformulação do quadro partidário - o que poderá ser verificado ao término da atual legislatura da Assembleia Nacional.

O mecanismo do referendo, citado na dimensão "participação", também se mostra como uma importante ferramenta de soberania popular e contestação pública, pelo meio da qual os cidadãos possuem certo controle perante as ações dos governantes, principalmente o referendo de tipo "revogatório".

\section{Accountability horizontal}

Accountability horizontal seria o mesmo papel de "monitoramento político" da accountability vertical só que sendo exercido por outros funcionários do Estado ou instituições estatais que possuam a autoridade legal para exercê-la. Tal dimensão é comumente manifesta em atividades de monitoramento, investigação e enforcement ("aplicação") da lei, mediante agências governamentais independentes, como: a oposição parlamentar, uma corte constitucional, comissões contra a corrupção, um corte dos direitos humanos ou uma administração eleitoral independente. Sendo assim, o primeiro passo para a existência de accountability horizontal seria a divisão de poderes.

Nesse sentido, o Poder Público Nacional da Venezuela divide-se em cinco poderes: Legislativo, Executivo, Judiciário, Cidadão e Eleitoral, sendo os dois últimos incorporados pela nova Constituição. 0 Poder Legislativo é exercido pela Assembléia Nacional. O Poder Executivo, pela Presidência da República, pelo VicePresidente, pelos Ministros, pelo Conselho de Ministros, pela Procuradoria-Geral da República e pelo Conselho de Estado. O Poder Judiciário é exercido pelo Tribunal Supremo de Justiça, pelos Tribunais e Juízes. O Poder Cidadão, pelo Conselho Moral Republicano (integrado pelo Defensor do Povo, pelo Procurador-Geral e pelo Controlador-Geral). Os órgãos do Poder Cidadão são: o Ministério Público do Povo, o Ministério Público e a Controladoria-Geral da República. O Poder Eleitoral já teve seus órgãos descritos anteriormente. Assim, segundo a Constituição, o Poder Público Nacional é regulado em conformidade com o princípio da separação de poderes. 
Creio que o Poder Eleitoral cumpriria um importante papel de accountability, dada sua natureza autônoma e despartidarizada, considerando-se as devidas ressalvas. Esse poder buscaria regular as eleições em todos os níveis, punindo qualquer transgressão à Lei Orgânica Eleitoral que seja observada. 0 cumprimento de suas atribuições, porém, é bastante questionado, como visto quando do boicote dos oposicionistas às eleições de 2005, pela alegação de haver uma politização a favor do governo do Conselho Nacional Eleitoral, colocando em dúvida o grau de accountability do governo.

O Poder Cidadão também cumpre um importante papel de accountability. Segundo a Constituição, ele seria autônomo e com poder de atuação em escala nacional, detendo a função de prevenir, investigar e punir os fatos que atentem contra a ética pública, a moral administrativa, zelando pela boa gestão e pela legalidade no uso do patrimônio público e pelo cumprimento e aplicação do princípio da legalidade em toda a atividade administrativa do Estado. Segundo Diamond e Morlino (2005), a existência de um órgão de combate a corrupção, tal como o Ministério Público do Povo seria essencial às democracias contemporâneas.

Quanto à oposição parlamentar, esta também poderia cumprir um importante papel de monitoramento das ações do governo, mas, dado o boicote das eleições parlamentares e a criação do PSUV, o governo conta com uma oposição praticamente irrelevante na Assembleia Nacional, colocando mais uma vez em discussão se há órgãos que cumpram o papel de accountability horizontal no governo.

\section{Igualdade}

A igualdade, condição substantiva para a democracia, deve garantir que cada cidadão ou grupo de pessoas tenha os mesmos direitos e proteções legais, assim como um significativo e pronto acesso à justiça e ao poder. Assim, surge mais uma vez no debate o papel da educação e a questão das desigualdades sociais. A democracia pressupõe um mínimo de igualdade política e de acessibilidade à educação, fatores que dependem de uma igualdade de riqueza e de status (certo grau de igualdade socioeconômica para além da política). Para tal, os autores ressaltam o papel historicamente relevante de grupos autônomos e partidos políticos com- 
prometidos com as classes menos privilegiadas. Mas, além disso, é também crucial o papel do sistema legal, que garanta os direitos civis e políticos de grupos subordinados e vulneráveis.

Os dados do relatório "The Chávez Administration at 10 Years: The Economy and Social Indicators" (2009), uma publicação do Center for Economic and Policy Research (CEPR), mostram claramente os progressos alcançados pelo governo Chávez na dimensão igualdade, que creio ser uma das que mais foram priorizadas. 0 relatório aponta que houve um grande declínio na porcentagem de "pobres" e "extremamente pobres" na população. A porcentagem de "abrigados" em condições de pobreza caiu de 42,8\% para 26\% em 10 anos. A condição de extrema pobreza caiu de 16,6\% para 7\%. Observa-se também uma queda acentuada no nível de desigualdade, medidas pelo índice Gini. Desde a eleição de Chávez, o índice caiu em quase seis pontos, de $46,96 \%$ para $40,99 \%$.

Quanto aos índices de saúde, o índice de mortalidade infantil caiu de 21,4 para 14,2 mortes a cada 1.000 crianças nascidas vivas e os maiores avanços foram alcançados entre as crianças de 1 a 11 meses, em que o índice de mortalidade neonatal caiu em mais da metade. Os índices de segurança alimentar também apresentam grandes avanços (como o índice de consumo calórico), além do fato das mortes relacionadas à subnutrição caírem em mais de 50\% de 1998 a 2006 . Esses indicadores também se refletem no aumento da parcela da população com acesso a tratamento médico: há um aumento significativo das salas de emergência e prontos socorros.

Os avanços na educação também são substanciais, principalmente na educação superior. 0 grau de escolarização básico (do 1ำ ao 9o ano) aumentou de 85\% para 93,6\%, e o número de jovens matriculados no ensino secundário aumentou ainda mais, partindo de um quinto para mais de um terço da população. $O$ aumento no número de matriculados na educação básica representa $8,6 \%$ das crianças em idade de 5 a 14, ou quase meio milhão de crianças na escola, que de outra forma não teriam tido acesso a educação. Para o ensino secundário, o aumento significa que $14,7 \%$ das crianças com idades entre 15 a 19, ou cerca de 400.000 crianças, têm sido capazes de permanecer na escola como um resultado direto da melhoria dos investimentos sociais. 
Em relação ao ensino superior, em comparação com o ano escolar 19992000, o número de estudantes matriculados em cursos superiores cresceu 86\% em comparação com o ano escolar 2007-2008.

O grande impulsionador das políticas sociais do governo Chávez são as chamadas Misiones. Atualmente são cerca de 30 missões (programas sociais massivos e emergenciais que contam com recursos advindos diretamente da PDVSA, a estatal petroleira) que tratam das mais variadas questões sociais e evidenciam a prioridade dada à dimensão "igualdade". Algumas das mais relevantes na área de saúde são:

- Misión Alimentación: também conhecida como Mercal, tem o objetivo principal de comercializar e estabelecer uma rede de mercados populares, com preços abaixo dos de mercado, visando à soberania alimentar da população, principalmente dos setores menos privilegiados. A Misión também tem relação direta com o Ministéro de Economia Solidária, criado no governo Chávez;

- Misión Barrio Adentro (I, II e III): tem como objetivo garantir o acesso universal a todas as formas de atendimento médico, pela criação de Consultórios, Clínicas Populares, Centros de Tecnologia, Centros de Diagnóstico e Reabilitação Integral;

- Misión José Gregório Hernández: tem o objetivo de levar atenção primária às pessoas portadoras de necessidades especiais.

E na área de Educação têm-se:

- Misión Ribas: programa educativo que visa garantir a continuidade dos estudos daqueles adultos que não tiveram essa oportunidade;

- Misión Robinson: em parceria com o exército, trata-se do programa de erradicação do analfabetismo, que levou a Organização das Nações Unidas para a Educação, a Ciência e a Cultura (Unesco) a declarar a Venezuela como o terceiro país das Américas a tornar-se um “Território Livre do Analfabetismo" (ao lado de Canadá e Cuba); 
- Misión Sucre: iniciativa que tem o objetivo de potencializar a sinergia institucional e a participação comunitária, para garantir o acesso universal à educação universitária, culminando na criação da Universidad Bolivariana de Venezuela, a UBV.

Os resultados alcançados por essas missões - evidenciados no relatório do CEPR - mostram o peso que o governo coloca na dimensão igualdade do modelo aqui utilizado. 0 orçamento total dos programas sociais do governo Chávez alcançaram os 2 bilhões de dólares em 2004 (BECERA, 2006) e, segundo estimativas, pode ter alcançado 4 bilhões de dólares em 2010.

\section{Responsividade}

A responsividade de um governo democrático, nas palavras de Powell Jr. (2005), ocorre quando o processo democrático induz os atores políticos a fazer e implementar as políticas que os cidadãos querem. Isso traz a discussão acerca da dificuldade de todas as pessoas em identificarem seus interesses quando as escolhas políticas requerem conhecimento técnico ou específico de avaliação, mais uma vez surge a variável "educação". Assim, um governo democrático de qualidade deve ter a capacidade de agregar as preferências e transformá-las em políticas públicas, de governar com responsabilidade, não somente com "responsividade" e sendo de manter a soberania popular.

Um importante elemento de responsividade implementado pelo governo e de caráter único no mundo é o tradicional programa televisivo "Aló Presidente". Com uma média superior a quatro horas de transmissão ininterrupta, o programa divide-se em: a) prestação de contas da agenda presidencial da semana anterior; b) anúncio de novas medidas; c) propaganda e informação detalhada das iniciativas do governo, geralmente com a participação de ministros e quadros técnicos; d) contatos telefônicos diretos com a população, em sua maioria, residente na região onde o programa é gravado; e) variedades como sugestões de livros, divulgação de iniciativas de diversos tipos de entidades. 0 programa é transmitido sempre de diferentes locais do país, desde um museu militar até uma grande favela. 
O programa foi transmitido pela primeira vez em 23 de maio de 1999 e, nas palavras do governo, o "Aló Presidente vem a ser uma das principais ferramentas de comunicação que tem e requer a população venezuelana para se informar de maneira veraz e oportunamente".

Considerando um contato direto da população com os representantes do governo e não só com presidente, muitas leis foram encaminhadas ao Poder Legislativo e muitas obras de variadas proporções foram realizadas, em sua maioria como parte das Misiones. Em uma sociedade onde os meios de comunicação se encontram cada vez mais difundidos, o governo optou por inserir-se nesse sistema e utilizá-lo em seu benefício.

Apesar da grande propaganda em torno das iniciativas do governo nas transmissões, a população conta com um importante canal de comunicação direto com o Poder Executivo pelo meio do qual elas podem expressar seus anseios e até fazer denúncias. A cada programa são em torno de cinco ligações atendidas ao vivo, mas segundo os produtores do programa são cerca de 1000 ligações por programa, sendo todas elas anotadas e repassadas para o órgão do governo a que compete a questão.

\section{Considerações finais}

Ao longo da análise, apesar das limitações deste trabalho, aplica-se o modelo de Qualidade da Democracia de Diamond e Morlino a um estudo de caso, na tentativa de explicitar as dimensões as quais o governo venezuelano tomaria como prioridade em possível detrimento de outras. Nesse sentido, as dimensões nas quais se pode fazer uma avaliação positiva do governo são primado da lei, participação, igualdade, responsividade e accountability vertical. Aquelas em que a democracia venezuelana apresenta problemas seriam competição, liberdade e accountability horizontal. A hipótese dos autores de que há trade-offs entre as dimensões do modelo se sustenta e foi demonstrada com dados socioeconômicos e fatos ocorridos desde a chegada de Chávez ao poder.

A dimensão "primado da lei" se mostrou importante para os venezuelanos. Durante o período em que a Assembleia Constituinte exercia seus trabalhos, a mo- 
bilização política foi bastante grande, seja por alguns setores da sociedade civil e da população em geral, seja pelas diferentes forças políticas que compunham o sistema partidário. Porém, pode-se observar a relevância dada ao primado da lei principalmente quando da tentativa de golpe contra o governo, em abril de 2002. Na ocasião, uma multidão de milhares de pessoas dirigiu-se ao Palácio de Miraflores, sede do governo, para defender sua Constituição amparando-se em seus próprios artigos. 0 então procurador-geral da República, Daniel Romero, já havia anunciado que aquela Constituição não seria mais respeitada e que o novo Poder Legislativo que surgia com o golpe teria funções constituintes em questão de meses (MARINGONI, 2004).

A dimensão "participação" foi exemplificada pela quantidade de referendos aplicados desde a chegada de Chávez à presidência. Dado o fato de que o voto não é obrigatório na Venezuela, considero também os índices de comparecimento às urnas nesses mesmos referendos. Como resultado, observa-se que esses índices se mostraram bastante positivos.

A dimensão "igualdade" aparenta ser a grande prioridade da democracia venezuelana. Tal fato poderia estar associado aos elevados índices de pobreza observados antes da eleição de 1998. As missiones são o grande carro chefe do governo, tendo impacto direto na grande proporção dos setores menos privilegiados da sociedade venezuelana. Os números do relatório "The Chávez Administration at 10 Years: The Economy and Social Indicators" (2009) e o crescente orçamento dos programas comprovam essa hipótese.

As dimensões "responsividade" e "accountability vertical" estão intimamente associadas. Sendo assim, os referendos aplicados e o programa televisivo do presidente, mesmo com as ressalvas feitas, cumprem um importante papel ao manterem a população informada e em uma posição que permite aos cidadãos fazerem uma avaliação do governo até então.

A variável "competição" mostra ser problemática, pois apesar de o governo realizar eleições regulares e a Constituição garantir o direito de associação, o governo possui um partido muito mais forte que qualquer outro. As aparições semanais do presidente, apesar de colaborarem para as dimensões "accountability ver- 
tical" e "responsividade", também desequilibram a correlação de forças existente entre os partidos em favor do governo.

Quanto à dimensão "liberdade", os dados da organização Freedom House colocam a Venezuela como "parcialmente livre". A avaliação feita pela Freedom House toma como prioridade a dimensão "liberdade" para que um governo seja classificado como sendo democrático, sem levar em conta outros fatores que podem ser importantes, como a igualdade social e a responsividade. Mesmo assim, a análise quanto à não renovação da concessão de radiodifusão da RCTV, um canal de claro posicionamento opositor ao governo, demonstra que essa dimensão pode apresentar problemas na democracia venezuelana.

A qualidade do "accountability horizontal" também deve ser questionada. Apesar da existência da divisão de poderes no sistema político venezuelano e da radical mudança promovida pela nova Constituição com a criação dos Poderes Eleitoral e Cidadão, estes recebem duras críticas quanto à sua politização, colocando em dúvida se eles realmente cumpririam um papel de verificação e monitoramento como forças autônomas ao governo.

Nesse sentido, procurei sustentar a tese de que a democracia de um determinado país se baseia em escolhas por parte de governantes e também por parte dos governados. A democracia venezuelana, após a eleição de Hugo Chávez, opta por enfatizar certas dimensões como participação e igualdade em possível detrimento de outras, como competição e liberdade - hipótese aqui comprovada.

As críticas dirigidas ao atual regime venezuelano argumentam que o governo Chávez caminha inexoravelmente rumo a um autoritarismo. Essas críticas partem principalmente de governos em que vigora um modelo liberal de democracia, baseando suas críticas em um juízo de valor. Segundo Philippe C. Schmitter (2005), autor do capítulo acerca da accountability do modelo analítico utilizado, esta seria uma das falácias que poderiam surgir das análises das novas democracias: o partisanship. É tentador presumir que a democracia analisada deveria estar fazendo aquilo que o analista gostaria que ela fizesse substantivamente. Aqueles que criticam o sistema venezuelano tomam como parâmetro um modelo liberal de democracia, avaliando sempre de maneira negativa um modelo como o da Venezuela. Por fim, vou de encontro à conclusão alcançada pelo venezuelanista norte- 
americano Michael Coppedge (s/d, citado em NETo, 2003). 0 que há hoje na Venezuela é um conflito entre duas visões de democracia. Uma visão calcada na noção de soberania popular, mais participativa no nível societário, e não só no nível eleitoral; defendida pelo chavismo, reivindicando para o seu líder um mandato amplo supostamente conferido pelo eleitorado. E uma visão de democracia liberal advogada pelos opositores de Chávez, visão que sustenta a necessidade de limites ao governo e respeito ao rol clássico de direitos para que exista realmente um regime democrático. A análise desenvolvida aqui procura, em partes, evidenciar esse dilema, demonstrando o tipo peculiar de democracia existente na Venezuela hoje em dia, que opta por dar ênfase a dimensões as quais outros regimes democráticos não priorizam.

\section{Referências}

ARbeX JR., J. (2004). "Entrevista do presidente Hugo Chávez". Revista Caros Amigos, Editora Casa Amarela, ano VIII, n. 89, ago.

BeCERA, M. P. (2006). "Clientelism and Social Funds: Empirical Evidence from Chávez's 'Misiones' Programs In Venezuela”. Instituto de Estudios Superiores de Administración (IESA), Caracas, Venezuela, May.

CARMonA, E. (2007). "Salvador Allende se revolve em sua tumba: senadores socialistas comparam Chávez a Pinochet". Folha de S. Paulo, São Paulo, 1 jul. Coluna do jornalista Jânio de Freitas da edição online.

Cipriani, J. B. (2007). Poder Popular, Poder Constituyente. Caracas, Inversiones Gamaprisma C. A.

CooppedGe, M. (s/d). "Popular Sovereignty versus Liberal Democracy in Venezuela". In: Domínguez, J. I.; SHIFTER, M. (orgs.). Constructing Democratic Governance. Baltimore, The Johns Hopkins University Press (no prelo).

Diamond, L.; Morlino, L. (eds.). (2005). Assessing the Quality of Democracy. Baltimore, Johns Hopkins University Press.

DicionáRIO Aurélio da Língua Portuguesa. (1998). Rio de Janeiro, Editora Nova Fronteira.

FríAS, H. R. C. (2007). "El discurso de la unidad". Ediciones Socialismo del Siglo XXI, n. 1 , jan.

. (2008). “La democracia poderosa y el liderazgo”. Coleção Discursos, Ministério do Poder Popular para a Comunicação e a Informação, maio.

LAPALOMBARA, J. (1982). A política no interior das nações. Brasília, Editora Universidade de Brasília. 
LijPhART, A. (2003). Modelos de democracia. Desempenho e padrões de governo em 36 países. Civilização Brasileira, Rio de Janeiro.

Maringoni, G. (2004). A Venezuela que se inventa. São Paulo, Fundação Perseu Abramo.

Mccoy, J. (2005). "O referendo na Venezuela: um ato em um drama inacabado". Novos Estudos - CEBRAP, São Paulo, n. 72, jul. Disponível em: <www.scielo.br/scielo. php?script $=$ sci arttext\&pid=S010133002005000200001\&lng=en\&nrm =iso $>$.

Ministerio del Poder Popular para la Comunicación y la Información. (2007). Libro Blanco sobre RCTV. Caracas, Venezuela.

MoISÉs, J. A. (2011). “O desempenho do Congresso Nacional no presidencialismo de coalizão (1995/2006)”. In: MoIsÉs, J. A. (org.). O papel do Congresso Nacional no presidencialismo de coalizão. 1. ed. São Paulo e Rio de Janeiro, Núcleo de Pesquisa de Políticas Públicas/USP e Fundação Konrad Adenauer, vol. 1, p. 7-28.

Moisés, J. A; CARneiro, G. P. (2008). “Democracia, desconfiança política e insatisfação com o regime - o caso do Brasil”. Opinião Pública, Campinas, vol. 14, n. 1, jun., p. 1-42.

Morlino, L. (2008). "Democracy and changes: how research tails reality". West European Politics, vol. 31, n. 1-2, p. 40-50.

NETO, O. A. (2003). "De João Goulart a Hugo Chávez: a política venezuelana à luz da experiência brasileira". In: GUIMARÃES, S. P.; CARDIM, C. H. Venezuela: visões brasileiras. Brasília, Instituto de Pesquisa de Relações Internacionais Fundação Alexandre de Gusmão.

O`Donnell, G. (1998). "Poliarquias e a (in)efetividade da lei na América Latina”. Novos Estudos - CEBRAP, São Paulo, n. 51, jul., p. 37-61.

. (2005). "Why the Rule of Law Matters". In: Diamond, L.; Morlino, L. (eds.). Assessing the Quality of Democracy. Baltimore, Johns Hopkins University Press.

POWELl JR., G. B. (2005). "The chain of responsiveness". In: Diamond, L.; Morlino, L. (eds.). Assessing the Quality of Democracy. Baltimore, Johns Hopkins University Press.

Rey, J. C. (1980). Problemas socio-políticos de América Latina. Caracas, Editorial Ateneo y Editoria Jurídica Venezolana.

SCHMitTER, P. C. (2005). "The ambiguous virtues of accountability". In: DiAmond, L.; Morlino, L. (eds.). Assessing the Quality of Democracy. Baltimore, Johns Hopkins University Press.

Venezuela. (1999). Constitución de La República Bolivariana de Venezuela. Gaceta Oficial de La República Bolivariana de Venezuela.

. (2002). Ley Orgánica del Poder Electoral. Disponível em: <www.unhcr.org/ refworld/docid/44a103f34.html>. Acesso em: jan. 2010.

VILLA, R. D. (2005). "Venezuela: mudanças políticas na era Chávez". Estudos Avançados, São Paulo, vol. 19, n. 55, dez. Disponível em: <www.scielo.br/scielo.php?

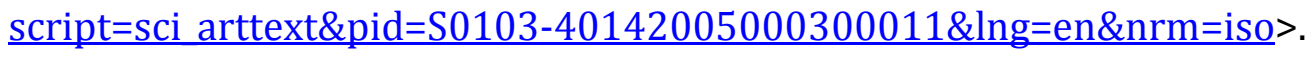


WeisBrot, M.; RaY, R.; SAndoval, L. (2009). "The Chávez Administration at 10 Years: The Economy and Social Indicators". CEPR, fev. Disponível em: <www.cepr.net/ documents/publications/venezuela-2009-02.pdf>.

Recebido em setembro/2011

Aprovado em dezembro/2011 